\title{
Peran guru membiasakan menyanyikan lagu nasional sebagai upaya pembentukan nasionalisme siswa
}

\author{
Nyai Yati ${ }^{a, 1}{ }^{*}$, Fitri Silvia Sofyan ${ }^{b, 2}$, Nadya Putri Saylendra ${ }^{c, 3}$ \\ abc Pendidikan Pancasila dan Kewarganegaraan, Universitas Buana Perjuangan, Karawang, Indonesia \\ 1pk16.nyaiyati@mhs.ubpkarawang.ac.id* \\ *korespondensi penulis
}

\section{ABSTRAK}

Penelitian ini bertujuan untuk mendeskripsikan peran guru membiasakan menyanyikan lagu nasional sebagai pembentukan semangat nasionalisme siswa. Sejalan dengan tujuan peneliti tersebut maka dalam penelitian ini menggunakan metode penelitian deskriptifkualitatif. Subyek penelitian sebanyak 10 siswa kelas VIII dan 1 guru PPKn. Metode pengumpulan data adalah observasi, wawancara dan dokumentasi. Teknik pemeriksaan menggunakan Tringulasi.

Hasil penelitian sebagai berikut (1) guru berperan dalam membiasakan menyanyikan lagu nasional sebagai pembentukan semangat nasionalisme siswa dengan melakukan cara konsisten dalam membiasakan menyanyikan lagu nasional (2) lagu nasional berperan dalam pembentukan semangat nasionalisme siswa dilihat dari adanya perasaan bertambah cinta pada tanah air siswa setelah menyanyikan lagu nasional (3) hambatan guru dalam membiasakan menyanyikan lagu nasional ada beberapa hambatan dimulai dari ketidak hafalkan siswa pada lirik dan nada lagu nasional dan kurang nya rasa khidmat siswa ketika menyanyikan lagu nasional membuat guru lebih kreatif lagu dalam membiasakan menyanyikan lagu nasional. Kesimpulanya guru berperan dalam membiasakan menyanyikan lagu nasional dilihat dari bertambahnya rasa cinta siswa pada tanah air setelah menyanyikan lagu nasional

\section{ABSTRACT}

This study aims to describe the role of the teacher in getting used to singing the national song as the formation of the spirit of nationalism in students. In line with the aims of these researchers, this study uses descriptive qualitative research methods. The research subjects were 10 class VIII students and 1 PPKn teacher. Data collection methods are observation, interview and documentation. The examination technique uses tringulation. The results of the research are as follows (1) the teacher plays a role in getting used to singing the national song as the formation of the spirit of nationalism of students by doing a consistent way in getting used to singing the national song (2) the national song plays a role in forming the spirit of nationalism of students as seen from the feeling of increasing love for the student's homeland after Singing the national song (3) the obstacles of the teacher in getting used to singing the national song there are several obstacles starting from the students not memorizing the lyrics and tones of the national song and the lack of a sense of solemnity from the students when singing the national song making the teacher more creative in getting used to singing the national song. In conclusion, the teacher plays a role in getting used to singing the national song, seen from the increased love of students for the country after singing the national song

\section{Sejarah Artikel}

Diterima : 25 Mei 2020

Disetujui : 28 Juli 2020

Kata kunci:

Peran Guru, Lagu Nasional, Nasionalisme

\section{Article's Information:}

Received: 25 May 2020

Accepted: 28 July 2020

\section{Keywords:}

The Role of Teachers

National Songs

Nationalism

\section{Pendahuluan}

Lagu nasional adalah suatu lagu yang diakui sebagai lagu resmi dan menjadi simbol negara atau daerah. Lagu nasional dapat membentuk identitas nasional suatu negara dan dapat digunakan sebagai ekspresi dalam menunjukan rasa nasionalisme dan patriotisme. Lagu nasional dapat digunakan berbagai hal. Seperti aktivitas olah raga antar negara yang biasanya di nyanyikan ketika upacara penyerahan mendali, upacara bendera merah putih dilaksanakan disetiap sekolah negri 
maupun sekolah swasta dinyanyikan dengan berdiri tegak dan menunjukan sikap hormat. Akan tetapi pada sekarang ini banyak generasi muda yang tidak menunjukan sikap hormat, seperti becanda ketika menyanyikan lagu nasional, merubah lirik lagu, tidak hafal lagu nasional dan tidak menghayati makna dari lagu nasional. Kurangnya motivasi dan peranan guru dalam membiasakan menyanyikan lagu nasional menyebabkan peserta didik tidak mengenali lagu nasional dan mengalami ketidak tertarikan peserta didik pada lagu nasional, padahal lagu nasional diajarkan pada sekolah dasar sampai perguruan tinggi untuk tujuan nasional. Lagu nasional seharusnya dijungjung tinggi dan dijadikan hal yang seharusnya dibanggakan, bukan ditinggalkan. Para peserta didik perlu memperkuat jati diri bangsanya dengan mengenali simbol-simbol negara dan identitas negara. Lagu nasional bagian dari identitas negara bila lagu nasional tidak dikenali generasi muda dan tidak disukai dapat menyebabkan kurangnya rasa nasionalisme terhadap tanah air. Perlunya mengetahui peran guru membiasakan menyanyikan lagu nasional sebagai pembentukan semangat nasionalisme siswa SMP. Dalam konteks persekolahan, pendidikan karakter yang terintegrasi dengan Pancasila dan Kewarganegaraan mampu mengembangkan karakter guna menghadapi revolusi industri 4.0 (Susanto et al., 2020). Berbagai upaya yang dilakukan ini bertujuan untuk membentukan karakter melalui pembiasaaan. Pembiasaan atau habituasi dapat dilakukan di sekolah dalam upaya mengembangkan karakter dan watak kewarganegaraan (Susanto \& Komalasari, 2015). Karakter bangsa inilah merupakan pondasi yang utama dalam membentuk nasionalisme siswa untuk menjadi warga negara yang baik dan cerdas. Karena dalam pembentukan semangat nasionalisme siswa dapat dilakukan dengan berbagai cara, salah satunya dengan membiasakan menyanyikan lagu nasional pada peserta didik. Sehingga akan menerapkan semangat nasionalisme pada kehidupan sehari-hari, sehingga siswa bisa menjadi pribadi yang nasionalis yang cinta pada tanah air. Berawal dari latar belakang diatas peneliti akan melakukan penelitian deskriptif. Peneliti mengambil judul Peran guru membiasakan menyanyikan lagu nasional sebagai pembentukan semangat nasionalisme siswa kelas VIII di Sekolah Menengah Pertama Karya Bhakti Kecamatan Kedungwaringin Bekasi.

\section{Metode}

Penelitian ini merupakan penelitian kualitatif, yaitu prosedur penelitian yang menghasilkan data deskriptif berupa kata-kata, gambar, dan bukan angka-angka, dari orang-orang atau perilaku yang dapat diamati. Dengan demikian, laporan penelitian akan berisi kutipan-kutipan untuk memberi gambaran penyajian laporan tersebut. Data tersebut berasal dari naskah wawancara, catatan lapangan, dokumen pribadi atau catatan atau memo. Dan dokumentasi resmi lainnya. Dengan memilih pendekatan ini diperoleh data berupa tingkah laku, ucapan, kegiatan dan perbuatan lainnya yang berlangsung dalam suatu penerapan metode saat proses penelitian berlangsung. Pemaparan data yang didapat dari informasi tersebut dijelaskan sewajar dengan tidak menghilangkan sifat keilmiahnya

\section{Hasil danPembahasan}

Selain menyampaikan informasi tugas guru juga memberikan teladan, menciptakan lingkungan pendidikan yang kondusif, membimbing mengajar dan melatih peserta didik dan menumbuhkan semangat nasionalisme salah salah satu caranya dengan membiasakan menyanyikan lagu nasional, tugas guru sangat dibutuhkan. Agar bisa menumbuhkan semangat nasionalisme, guru harus memiliki semangat nasionalisme dan patriotisme yang tinggi, berwawasan kebangsaan dan mengenali simbol-simbol negara. Lagu nasional juga bagian dari simbol negara agar peran guru membiasakan menyanyikan lagu nasional tercapai maka guru harus hafal lagu-lagu nasional mulai dari intonasi, lirik, sejarah, dan makna lagu nasional.

Peneliti melakukan teknik wawancara dan dokumentasi untuk memperoleh data dari peran guru membiasakan menyanyikan lagu nasional. Konsisten adalah kunci utama untuk membiasakan 
menyanyikan lagu nasional. Sebelum memulai pelajaran guru mengajarkan siswa untuk terbiasa menyanyikan lagu nasional dengan konsisten dilakukan berulang-ulang dilakukan terus-menerus sehingga menjadi kebiasaan. Bila guru tidak konsisten maka peranya tidak akan sampai bayangkan jika minggu ini tidak membiasakan menyanyikan lagu nasional minggu besok menyanyikan siswa nanti akan bingung. Siswa pun merasa senang saat guru mengajak menyanyikan lagu nasional selain menyenangkan menyanyikan lagu nasional sebelum belajar menambah semangat siswa dan menghilangkan kebosanan.

Selanjutnya langkah-langkah guru membiasakan menyanyikan lagu nasional adalah pertama dengan cara konsisten, kedua tegas, dan ketiga biasanya setiap pertemuan guru mengajak siswa menyanyikan lagu yang berbeda dan biasanya guru mengatakan lagu apa yang akan di nyanyikan pada pertemuan selanjutnya. Setelah siswa selesai menyanyikan lagu nasional baru guru mengatakan kepada siswa bahwa besok lagu yang akan dinyanyikan bersama sama adalah lagu Indonesia Raya atau Garuda Pancasila misalnya agar siswa yang tidak tau dan tidak hafal bisa mencari tahu terlebih dahulu. Siswa pun merasa senang ketika menyanyikan lagu nasional karna lebih mengenal lagu-lagu nasional menambah semangat akan tetapi kadang siswa sering becanda karna diganggu teman yang lain yang membuat siswa tidak kdimat ketika menyanyikan lagu nasional, nah disini lah peran guru harus lebih ditekankan lagi guru harus melihat situasi siswa. Saat peneliti melakukan observasi peneliti menemukan peran guru membiasakan lagu nasional cukup baik.

A. Peran guru membiasakan menyanyikan lagu nasional sebagai pembentukan semangat nasionalisme siswa

Peran guru membiasakan menyanyikan lagu nasional sangatlah berpengaruh, karena guru mempunyai kendali penuh didalam kelas menciptakan suasana yang menyenangkan, menghilangkan kebosanan selain memberikan materi guru juga mengajarkan semangat nasionalisme pada siswa agar siswa menjadi anak yang pintar, cerdas dan mencintai tanah air. Hal ini bisa di lihat dari bagaimana usaha guru berperan membiasakan menyanayikan lagu nasional dengan konsisten sehingga anak terbiasa dan peran guru tersampaikan dengan baik. Hal ini sesuai dengan teori peranguru menurut UU no. 14 tahun 2005 Tentang Guru dan Dosen, guru adalah pendidik profesional dengan tugas utama mendidik, mengajar, membimbing, mengarahkan, melatih, menilai, dan mengevaluasi peserta didik pada anak usia dini jalur pendidikan formal, pendidikan dasar, dan pendidikan menegah"

Guru adalah seseorang yang mentransfer informasi ke pada orang lain dengan senang hati dan tanpa paksaan guru juga seseorang yang mengajarkan kebaikan dan ilmu dari yang tidak tahu menjadi tahu, yang tidak bisa menjadi bisa, yang tidak mengerti menjadi mengerti seperti lilin di kegelapan cahayanya menunjukan arah yang lebih terang sejalan dengan teori:

"Pada kamus besar bahasa indonesia diungkapkan bahwa pengertian guru adalah orang pekerjaanya mengajar. Sedangkan secara istilah Ahmad tafsisr menjelaskan bahwa guru adalah orang yang bertanggung jawab terhadap berlangsungnya proses pertumbuhan dan perkembangan potensi anak didik, baik potensi kognitif, potensi efektif, maupun potensi psikomotoriknya" (Hasan Alwi dalam Novan Ardy 2019: 2)

Ketika dilingkungan sekolah guru menjadi oarang tua kedua siswa yang bertanggung jawab memantau dan membimbing siswa ke hal yang lebih baik lagi seperti mengajarkan semangat nasionalisme dilingkungan sekolah. Para orang tua menitipkan anaknya ke sekolah untuk 
mendapatkan pemahaman dan pengetahuan dan prilaku yang baik yang berguna untuk dirinya, orang tua dan lingkunganya.

\section{B. Peran lagu nasional dalam pembentukan semangat nasionalisme siswa kelas VIII}

Lagu adalah alat untuk menyampaikan pesan yang di tambahkan dengan nada, tanda dinamik dan instrumen yang membuat lagu bisa mewakili emosional seseorang, yang tersampaikan dengan cara yang lebih indah dan menarik. Tak heran bila banyak orang yang berperan melalui lagu seperti penulis lagu ia menyampaikan perasaanya melalui lagu seperti perasaan sedih, senang, dan gembira. Hal ini sama dengan teori yang dipaparkan dibawah ini:

"Lagu sebagai sebuah produk budaya, antara lain berbicara kehidupan sehari-hari, kondisi zaman pada saat lagu tertentu diciptakan. Dinyanyikan dan di terima oleh masyarakat. Untuk mengenang sebuh kejadian atau utuk mengenai seseorang bisanya lagu diciptakan karna begitu berpengaruh lagu dalam emosional manusia sehingga sebuah lagu bisa mewakili sejarah, seperti lagu kebangsaan yang mencerminkan keaadaan masyarakat indonesia pada waktu penjajahan". (Astuti dalam Dwi Patma 2016: 13)

Pengaruh lagu sangatlah besar perananya karna lagu mudah diingat, banyak orang yang menuangkan ceritanya pada lagu. Seperti lagu kebangsaan dibuat untuk menceritakan keadaan bangsa indonesia pada saat itu. Yang dikemas dengan begitu indah serta lirik-lirik yang mengandung arti semangat untuk bersatu dan memberikan pesan untuk mencintai tanah air. Agar peran guru terlaksana secara optimal guru seharusnya berkaloborasi dengan guru ekstrakulikuler paduan suara agar minat siswa menyanyikan lagu nasional bertambah. Banyaknya siswa yang belum hafal nada diperlukan pelatikan khusus mengenai nada siswa bisa mempelajari nada lagu nasional melalui ekstrakulikuler paduan suara. Nada lagu nasional diatur tidak bisa dinyanyikan dengan nada sembarangan hal ini juga harus diperhatikan guru agar siswa paham.

Hal ini dapat peneliti simpulkan bahwa, guru dalam berperan membiasakan menyanyikan lagu nasional guru tercapai dengan baik membuat siswa berpartisipasi, mengajak siswa berperan aktif dalam menghafal, melestarikan lagu nasional dan menjadikan lagu nasional sebagai salah satu cara mencintai tanah air. Dengan membiasakan menyanyikan lagu nasional dengan konsisten membuat siwa sadar dan terbiasa untuk menyanyikan lagu nasional dengan baik dan hormat. Sehingga siswa berpartisivasi dan semangat untuk belajar dan memjadi siswa yang memncintai tanah air.

Siswa adalah masa depan negara dan bagian dari aset yang negara miliki untuk menentukan kemajuan bangsa di masa depan. Siswa lah yang akan bertanggung jawab penuh dimasa mendatang menjaga kemerdekaan yang telah dititipkan oleh leluhur dan para pahlawan yang telah gugur. Untuk itulah pendidikan di sekolah harus menumbuhkan rasa nasionalisme kepada siswa agar membawa mereka kepada rasa cinta pada bangsa dan tanah air.

\section{Hambatan guru membiasakan menyanyikan lagu nasional dalam pembentukan nasionalisme siswa}

Tugas guru menumbuhkan semangat nasionalisme dengan memberitahukan awal mula nya para pahlawan memiliki semangat nasionalisme bangkit dari keterpurukan penjajahan dengan cara itu guru berharap siswa memahami arti nasionalisme dan mengetahui awal mula nasionalsime ada pada saat pertamakali munculnya organisasi budi utomo yang menjadi awal mula nya para pemuda bergerak bersatu untuk melawan para penjajah dan mengorbankan dirinya untuk kemerdekaan. Hal ini sejalan dengan teori:

"Nasionalisme pada hakikatnya merupakan suatu idiologi modern, seperti halnnya demokrasi dan komunisme. Bahkan kolonialisme dan imprelialisme merupakan bentuk dari 
nasionalisme yang bersifat ekspansif, masalah kebangsaan yang paling pokok, menurut aliran marxis, adalah titik pertemuan antara politik, teknologi dan transformasi sosial." ( Hosbawm, 1992)

"Dalam catatan sejarah perjuangan bangsa indonesia untuk mempertahankan kemerdekaan telah meningkatkan pasang surut. Untuk membebaskan diri dari cengkraman penjajah ternyata sangat sulit. Perjuangan yang hanya mengandalkan kekuatapun tradisional, bukan yang mampu mengusir penjajah dari bumi tanah indonesia sadar melawan kekalahan yang terus berlanjut itu, maka bangsa indonesia mulai mengubah perjuanganya. Ketika pada mulanya mengandalkan kekuatan otak (mind). Dengan perebutan semacam itu bangsa indonesia berhasil melepaskan diri dari penjajah." (Drs. Sudiyo, 2002)

Pada saat peneliti melakukan observasi, tugas guru dalam menumbuhkan semangat nasionalisme tersampaikan dengan baik dilihat dari guru selalu mengaikan materi ppkn dengan semangat nasionalisme, tetapi masih banyak siswa yangt tidak hafal akan lagu nasional membuat guru harus lebih kreatif lagi dalam membiasakan menyanyikan lagu nasional agar tidak adalagi siswa yang tidak hafal akan lagu nasional, sehingga siswa memiliki rasa ketertarikan kepada lagu nasional. Selain itu guru juga selalu memberi contoh menjadi warga negara yang baik di sekolah, di rumah maupun dalam bernegara. Dilakukan dengan hal-hal kecil seperti diajarkan untuk mencintai lingkungan sekolah, toleransi, mengingat kan kembali siswa kepada jasa para pahlawan dengan cara menyanyikan lagu nasional dengan khidmat.

\section{UcapanTerima Kasih}

Diucapkan terimakasih kepada semua pihak yang telah berkontribusi dalam penelitian ini, sehingga penelitian ini dapat terselesaikan dengan baik

\section{Referensi}

Ardi Novan. 2019. Pengembangan Profesi Keguruan pada Era Revolusi Industri 4.0. Gava Media. Yogyakarta

Hobsbawn, EJ. 1992. Nasionalisme Menjelang Abad 21. Yogyakarta. PT Tiara Wacana

Sudiyo, 2002. Pergerakan Nasionalisme Mencapai dan Mempertahankan Kemerdekaan. Jakarta: Reneka Cipta

Susanto, E., \& Komalasari, K. (2015). Pengaruh Pembelajaran, Habituasi Dan Ekstrakurikuler Terhadap Pembentukan Civic Disposition Siswa Sma Negeri Se-Kota Bandar Lampung. Jurnal Mimbar Demokrasi, 15(1).

Susanto, E., Putri, N., Sanusi, A. R., \& Sofyan, F. S. (2020). Pancasila and Civic Education as Reinforcement of the National's Character of High School Students in Karawang Regency to Face the Revolution Industry 4.0. 418(Acec 2019), 503-506. https://doi.org/10.2991/assehr.k.200320.095

Patma Dwi Sari. 2016. Peran Lagu Nasional dalam Pembentukan Nilai Karakter Siswa kelas IV Sekolah Dasar Negri di Kecamatan Tugu Kota. Semarang. Universitas Negri Semarang. Tidak diterbitkan

Safitri Dian. 2017. Konsep Nasionalisme Menurut Sayyid Muhammad dalam Kitab Al-Tahiyyah Wal al-Targhib Fi Al-Tabiyyah wal al-Tahzim dan Implikasinya pada Pengembangan Karakter Cinta Tanah Air. Istitut Agama Islam Negri Sukaharta. Tidak diterbitkan Undang-Undang Republik Indonesia Nomor 14 Tahun 2005. Tentang Guru dan Dosen. 